\title{
Development of Advanced High Lift Leading Edge Technology for Laminar Flow Wings
}

\author{
Michelle M. Bright ${ }^{*}$, Andrea Korntheuer ${ }^{\dagger}$, Steve Komadina ${ }^{\ddagger}$ \\ Northrop Grumman Aerospace Systems, El Segundo, CA, 90245, USA \\ John C. Lin ${ }^{\S}$ \\ NASA Langley Research Center, Hampton, VA, 23681, USA
}

\begin{abstract}
This paper describes the Advanced High Lift Leading Edge (AHLLE) task performed by Northrop Grumman Systems Corporation, Aerospace Systems (NGAS) for the NASA Subsonic Fixed Wing project in an effort to develop enabling high-lift technology for laminar flow wings. Based on a known laminar cruise airfoil that incorporated an NGASdeveloped integrated slot design, this effort involved using Computational Fluid Dynamics (CFD) analysis and quality function deployment (QFD) analysis on several leading edge concepts, and subsequently down-selected to two blown leading-edge concepts for testing. A 7-foot-span AHLLE airfoil model was designed and fabricated at NGAS and then tested at the NGAS 7' x 10' Low Speed Wind Tunnel in Hawthorne, CA. The model configurations tested included: baseline, deflected trailing edge, blown deflected trailing edge, blown leading edge, morphed leading edge, and blown/morphed leading edge. A successful demonstration of high lift leading edge technology was achieved, and the target goals for improved lift were exceeded by $30 \%$ with a maximum section lift coefficient $\left(C_{1}\right)$ of 5.2. Maximum incremental section lift coefficients $\left(\Delta C_{1}\right)$ of 3.5 and 3.1 were achieved for a blown drooped (morphed) leading edge concept and a non-drooped leading edge blowing concept, respectively. The most effective AHLLE design yielded an estimated $94 \%$ lift improvement over the conventional high lift Krueger flap configurations while providing laminar flow capability on the cruise configuration.
\end{abstract}

\section{Nomenclature}

c $\quad=$ reference cruise airfoil chord, 30 inches

$\mathrm{C} \mu \quad=$ momentum coefficient, $\mathrm{m}_{\mathrm{dot}} \mathrm{u}_{\mathrm{jet}} /(\mathrm{qS})$

$\mathrm{C} \mu 1=\mathrm{C} \mu$ for forward-slot blowing at $0.01 \mathrm{c}$

$\mathrm{C} \mu 2=\mathrm{C} \mu$ for mid-slot blowing at $0.10 \mathrm{c}$ for LAVLET configuration and at $0.12 \mathrm{c}$ for MOLEC configuration

$\mathrm{C} \mu 3=\mathrm{C} \mu$ for aft-slot blowing at $0.80 \mathrm{c}$

$\mathrm{C}_{1} \quad=$ section lift coefficient

$\mathrm{C}_{1, \max }=$ maximum section lift coefficient

$\mathrm{C}_{\mathrm{m}} \quad=$ section moment coefficient about 0.25 mean aerodynamic chord

$\mathrm{Cp} \quad=$ pressure coefficient, $(\mathrm{P}-\mathrm{Ps}) / \mathrm{q}$

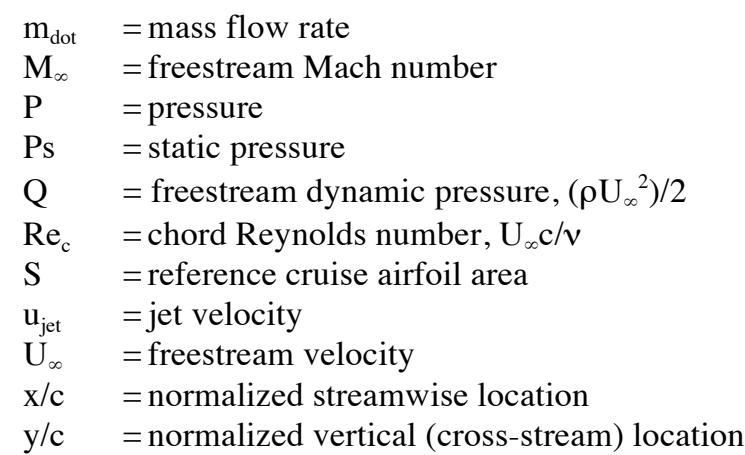

\footnotetext{
* Propulsion Engineer, Flight Analysis Department, Northrop Grumman Aerospace Systems, AIAA Senior Member ${ }^{\dagger}$ Aerospace Engineer, Aerodynamics Analysis Department, Northrop Grumman Aerospace Systems, AIAA Member

* Aerodynamics Analysis Department Manager, Northrop Grumman Aerospace Systems, AIAA Associate Fellow

${ }^{\S}$ Aerospace Engineer, NASA Langley Research Center, Flow Physics \& Control Branch, MS170, AIAA Associate Fellow
} 


\begin{tabular}{|c|c|c|c|}
\hline \multicolumn{4}{|c|}{ Greek } \\
\hline$\alpha$ & $=$ angle of attack, degrees & $\rho$ & $=$ density \\
\hline$\Delta$ & $=$ differential value & $v$ & $=$ kinematic viscosity \\
\hline \multicolumn{4}{|c|}{ Abbreviations } \\
\hline $\begin{array}{l}\text { AHLLE } \\
\text { CFD }\end{array}$ & $\begin{array}{l}=\text { Advanced High Lift Leading Edge } \\
=\text { computational fluid dynamics }\end{array}$ & NGAS & $\begin{aligned}= & \text { Northrop Grumman Corporation, } \\
& \text { Aerospace Systems }\end{aligned}$ \\
\hline $\begin{array}{l}\text { GCNS } \\
\text { HP }\end{array}$ & $\begin{array}{l}=\text { generalized compressible Navier-Stokes } \\
=\text { high pressure }\end{array}$ & NPR & $\begin{array}{c}=\text { nozzle pressure ratio (total to static } \\
\text { pressure ratio): NPR1, NPR2. NPR3 }\end{array}$ \\
\hline LAVLET & $\begin{array}{l}=\text { Laminar Airfoil Virtual Leading Edge } \\
\text { Technology }\end{array}$ & & $\begin{array}{l}\text { correspond to } \mathrm{C} \mu 1, \mathrm{C} \mu 2, \mathrm{C} \mu 3 \text {, } \\
\text { respectively }\end{array}$ \\
\hline LE & $=$ leading edge & QFD & $=$ quality function deployment \\
\hline MOLEC & $=$ Multi-Objective Leading-Edge Concept & SFW & $=$ Subsonic Fixed Wing \\
\hline NASA & $\begin{array}{l}=\text { National Aeronautics and Space } \\
\text { Administration }\end{array}$ & $\begin{array}{l}\text { TE } \\
\text { TRL }\end{array}$ & $\begin{array}{l}=\text { trailing edge } \\
=\text { technology readiness level }\end{array}$ \\
\hline NLF & $=$ natural laminar flow & & \\
\hline
\end{tabular}

\section{Introduction}

JASA's Subsonic Fixed Wing (SFW) Project is pursuing enabling high-lift technology for laminar flow wings. 1 One major challenge for laminar flow wings is that all modern commercial transport aircraft require retractable high-lift systems (i.e., slat and flaps) during take off and landing. The current mechanized leading-edge devices result in unavoidable steps and gaps that cause boundary-layer transition when stowed, making them incompatible with laminar flow at cruise [1]. The Advanced High-Lift Leading-Edge (AHLLE) task was aimed to meet or exceed the existing high-lift requirements during take off and landing while being compatible with laminar flow at cruise conditions. Gains in maximum lift coefficient could potentially reduce wetted area and parasitic drag and therefore fuel consumption. Without resizing the wing, introducing advanced high-lift capabilities into the wing would allow for the use of additional regional airports to reduce delay times in the National Aerospace System (NAS) and to meet aggressive fuel, emissions, and noise reduction goals. Collins [2] reported that a high-lift system compatible with a laminar flow wing is a dual-use technology, which enhances short takeoff and landing (STOL) capability and fuel savings.

Over the last 20 years, there is a foundation of progress in the aerospace industry with regards to laminar flow control research and flow control technology. Several Northrop Grumman research programs have advanced the technology readiness level (TRL) to 3. These research efforts included conceptual design studies (i.e., Laminar Airfoil Virtual Leading Edge Technology (LAVLET) and Multi-Objective Leading-Edge Concept (MOLEC) [3]), fabrication and test for high lift mobility configurations (i.e., Integrated Propulsion, Lift, and Control System (IPLC) $[4,5]$ ), and development of laminar flow technology (i.e., Surface Excrescence Transition Study (SETS) [6] and High Lift-Over-Drag Active Wing (HiLDA) [7]). The maturation of AHLLE technology would require the incorporation of lessons learned from these previous efforts into a building block plan that focuses on CFD aerodynamic analysis, propulsion design to achieve the desired blowing effectiveness for flow control, detailed model design to integrate the challenging design strategy, and ground test for validation. Several new and innovative approaches were also developed to deal with the challenges faced by coupling high lift technology compatible with laminar flow.

The NASA SFW project selected Northrop Grumman under the NRA N+3 for the AHLLE task to explore various leading edge (LE) concepts of achieving high lift on a wing section compatible with laminar flow. The task used CFD and QFD analyses to down-select to two concepts for wind tunnel testing. The ground-testing portion was the main emphasis of this research task and this paper.

\section{Concept Development and Down-Selection}

Northrop Grumman has leveraged its extensive history of laminar flow research and experimentation. A known natural laminar flow airfoil was selected as the baseline cruise configuration. The baseline cruise geometry and its associated pressure distribution with those of a NASA natural laminar flow (NLF) airfoil, HSNLF(1)-0213, are shown in Figure 1. An analytical investigation was performed initially to identify and quickly assess ten AHLLE configurations best suited for reconciling high-lift and laminar-flow wing design. The AHLLE concepts were computed using 3D viscous Navier-Stokes CFD to perform parametric studies on various LE blowing and drooping 
concepts for achieving high lift in the absence of a leading-edge slat. The computational tool used was a NGAS in-house proprietary finite-volume generalized compressible Navier-Stokes (GCNS) code [8]. This code has an extensive validation background on unconventional configurations and across the flow regime of interest [9].

Configuration selection was based on a QFD tool to provide ranking of the high-lift configurations identified in the concept development. The weighted ranking criteria include: laminar flow compatibility, lift performance, weight, noise, complexity, power requirement, TRL input, affordability, reliability, maintainability (see Figure 2). Two AHLLE concepts were down-selected from the ten initial concepts for further aerodynamic analysis and wind tunnel test (see Figure 3).

The first selection was a blown leading edge concept leveraged on a prior Air Force Research Laboratory (AFRL) funded Laminar Airfoil Virtual Leading Edge Technology (LAVLET) study. The LAVLET configuration has leading edge blowing at $1 \%$ and $10 \%$ of the cruise chord. The second selection was a 50\%-deployed drooped leading edge (or morphing) concept with blowing on its shoulder at $12 \%$ of the cruise chord. The morphing part (seamless drooped LE) of the second concept was leveraged on a previous NASA-funded Multi-Objective Leading Edge Concept (MOLEC) study. Both leading-edge blowing concepts assumed the utilization of an NGAS-developed integrated slot design that enables laminar flows during cruise. These two AHLLE configurations also shared the same simple, 45-degree, trailing edge (TE) flap that features a blowing slot at $80 \%$ of the cruise chord, as illustrated in Figure 3.

The down-selected AHLLE concepts were further analyzed by running the GCNS code in full $3 \mathrm{D}$ to perform additional LE blowing studies with the wind tunnel walls. Aerodynamic effects on high lift were assessed for an in-depth understanding of the performance trades. The aerodynamic CFD analysis was also used to guide pressure tap placement, and propulsion analysis was used to design internal cavity geometry of the high pressure blown slot configurations.
- Baseline AHLLE Airfoil

- NASA HSNLF(1)-0213 2D Airfoil

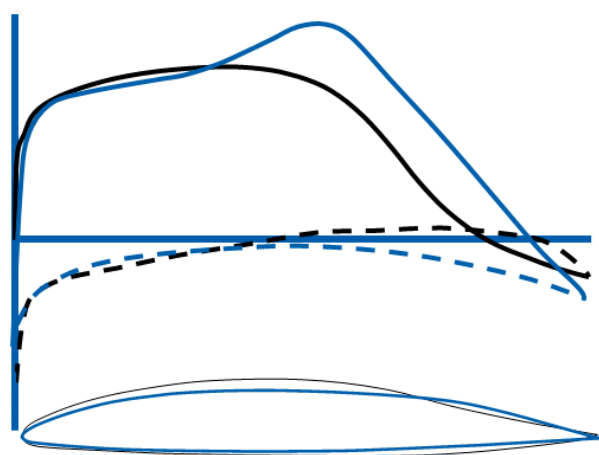

Figure 1. Baseline NLF cruise airfoil.

\begin{tabular}{ccll} 
Weighting & Average Dev & & Assessment Criteria \\
\cline { 1 - 3 } $\mathbf{2 7 . 8} \%$ & $3.9 \%$ & & Laminar Flow Compatibility \\
$18.3 \%$ & $4.7 \%$ & & Lift Performance \\
$7.5 \%$ & $2.8 \%$ & & Weight \\
$7.0 \%$ & $2.6 \%$ & Noise \\
$6.1 \%$ & $1.5 \%$ & Complexity \\
$11.8 \%$ & $3.8 \%$ & Power Requirement \\
$4.1 \%$ & $2.7 \%$ & TRL Input \\
$3.9 \%$ & $0.6 \%$ & Affordability \\
$6.9 \%$ & $2.2 \%$ & Reliability \\
$6.7 \%$ & $2.4 \%$ & Maintainability \\
\hline
\end{tabular}

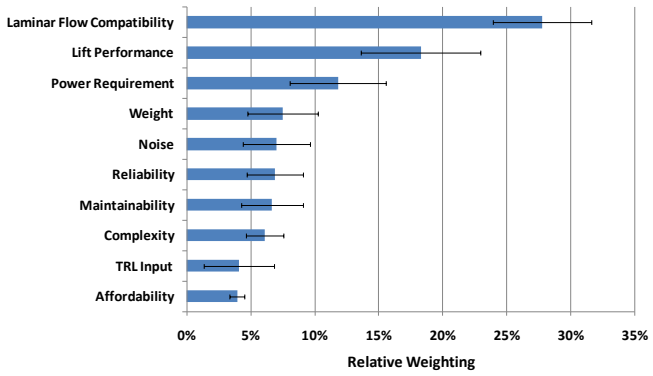

Figure 2. Relative rankings and weighting assessment factors for QFD.
AHLLE Configuration 1 (LAVLET)

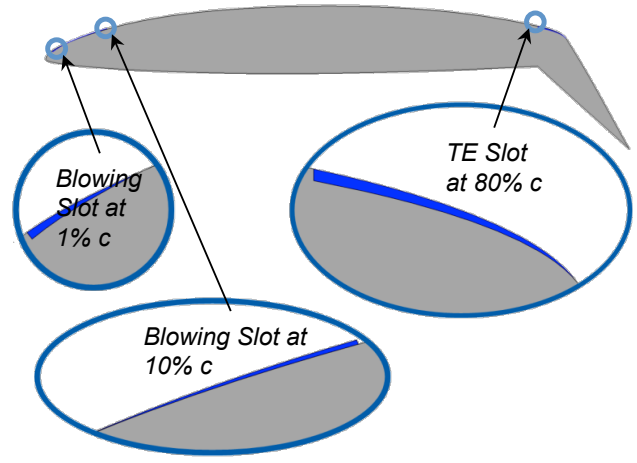

AHLLE Configuration 2 (MOLEC)

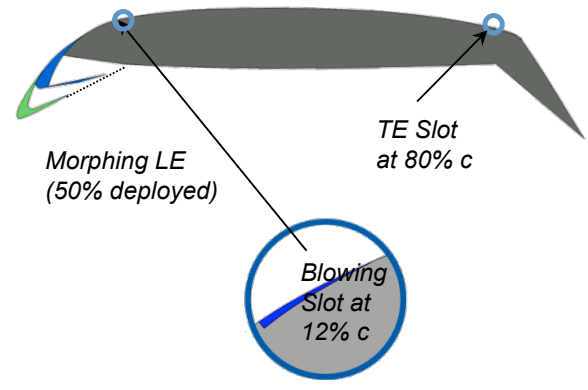

Figure 3. Down-selected AHLLE configurations. 


\section{Facility Description}

The Northrop Grumman 7' x 10' Low Speed Wind Tunnel at Hawthorne, CA (see Figure 4) was used for the ground testing portion of the two down-selected AHLLE concepts. It is an atmospheric, closed return tunnel with a test section of 7 -ft high, $10-\mathrm{ft}$ wide, and $20-\mathrm{ft}$ long. The tunnel can reach a maximum dynamic pressure (q) of 200 psf $\left(\mathbf{M}_{\infty}=0.37\right)$ with an empty test section. The facility has an auxiliary highpressure air supply system capable of supplying $2 \mathrm{lb} / \mathrm{s}$ of airflow continuously. The AHLLE investigation was conducted at a nominal condition of $\mathrm{q}=30 \mathrm{psf}, \mathrm{M}_{\infty}=$

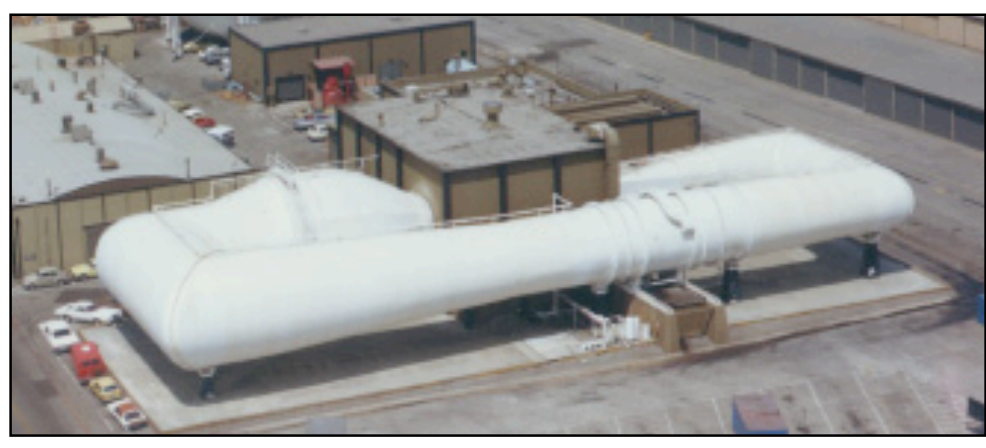

Figure 4. Northrop Grumman 7' x 10' Low Speed Wind Tunnel. 0.14 , and $\operatorname{Re}_{\mathrm{c}}=1$ million.

\section{Model Description}

The baseline laminar cruise airfoil model has an overall model span of 84 inches and a chord (c) of 30 inches. The blowing slot has a span of 76 inches with 4 inches on either end not blown. In addition to the baseline 2D airfoil, two AHLLE (i.e., LAVLET and the MOLEC blown LE designs with a 45-degrees deflected trailing edge) concepts were designed and built for high lift testing in the absence of a leading-edge slat. The two AHLLE models share common aluminum center body with the baseline airfoil. The center body was designed to allow for build-up of the model leading edge and trailing edge components. The trailing edge pieces were grown from Bluestone, a rapid prototyping material, and the leading edge pieces were made from either aluminum (LAVLET) or Bluestone (MOLEC). Flex lines attached through the floor of the wind tunnel to supply high pressure air to each of the model plenum cavities for the three blown slots: $1 \%$ and 10\% chord LE slots on LAVLET, a 12\% chord LE slot on MOLEC, and a common $80 \%$ chord TE slot on all configurations. Each slot location is pressurized by a dedicated continuous plenum. As an example, Figure 5 illustrates the blowing slot locations and the plenum layouts of the LAVLET model.

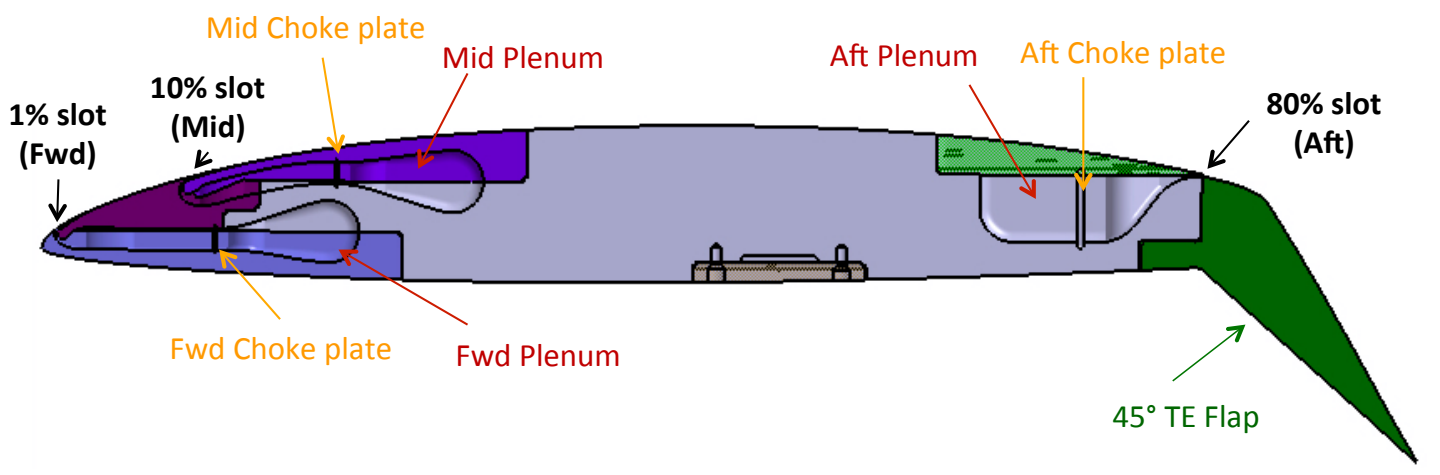

Figure 5. Blowing slot locations and the plenum layouts of the LAVLET model.

Facility high-pressure (HP) air is delivered to and stored in a test-specific HP Plenum. The flow branches from HP Plenum to 3 supply arms, each with a control valve to vary nozzle pressure ratio (NPR) for the model blown slot from 1.0 (off) to 2.0. A safely valve is connected to each control valve to prevent over pressurization of the model. Downstream of each control valve is a critical-flow venturi to meter the mass flow. Each venturi is connected to a flex line, which in turn is connected to a model supply line. All supply lines reside beneath the tunnel floor. The model supply lines mount directly to each of the model plenums. Flow in each model plenum passes through a choke plate to achieve uniform flow along the span of the blown slot. Through monitoring and examining the discharge coefficients throughout the test, the choke plates in all 3 plenums (forward, mid, and aft) were verified as choked and performed as expected. In addition, handheld surveys were used to document slot flow uniformity for all three locations (forward, mid, and aft) by moving a total probe along length of slot, at fixed NPR. 
The AHLLE airfoil model is equipped with 64 and 70 static pressure taps for the LAVLET and MOLEC configurations, respectively. There are 30 taps distributed along the centerline $(1 / 2$ span $)$ of the LAVLET configuration and 36 taps are distributed along centerline of the MOLEC configuration. Additional 17 taps are located on each of two streamwise rows located $1 / 3$ and $2 / 3$ of the model span for spanwise uniformity checks. The chordwise distributions of the pressure tap location were guided by the CFD predictions for the AHLLE configurations with the objective of minimizing error in computed section lift coefficient. An electronically scanned pressure (ESP) measurement system was used for speedy data acquisition. Integration of the centerline (dense row) pressure measurements yielded the lift and pitching moment results presented herein. Due to the limited quantity of taps the anticipated uncertainty in integrated forces and moments was estimated to be less than $3.5 \%$ for $\mathrm{C}_{1}$ and less than $8.5 \%$ for $\mathrm{C}_{\mathrm{m}}$ (based on limited CFD data).

\section{Results and Discussion}

The wind tunnel investigation started with the baseline cruise airfoil. For all baseline runs, the slots are taped over and the tape is removed later during blown runs. The trailing edge was then deflected 45 degrees for the start of high lift investigation and it is also used as a reference for the AHLLE configurations. The trailing edge slot located at $80 \%$ chord was blown for the study. Figure 6 displays results for section lift and pitching moment versus angle of attack to show the effectiveness of TE flap blowing. The NPR on the trailing edge is systematically increased to achieve a nominal blown flap value. Increased blowing on the $45 \mathrm{TE}$ flap improves $\mathrm{C}_{1, \max }$ but it also significantly decreases the stall angle of attack and increases negative pitching moment. This was predicted by the pre-test CFD aerodynamic analysis and the result is expected. A nominal blowing coefficient (C $\mu 3$ ) of 0.035 (NPR $=1.20$ ) was selected for the TE flap blowing on the remainder of the test on both the LAVLET and MOLEC configurations, because it maintained a positively sloped lift curve and a positive stall angle at low angles of attack $\left(\alpha \leq 2^{\circ}\right)$. As this was a proof of concept experiment for leading edge high lift concepts, the trailing edge blowing was not the emphasis of the study. Once a nominal NPR was achieved for maintaining a desirable lift characteristic, that value was fixed.
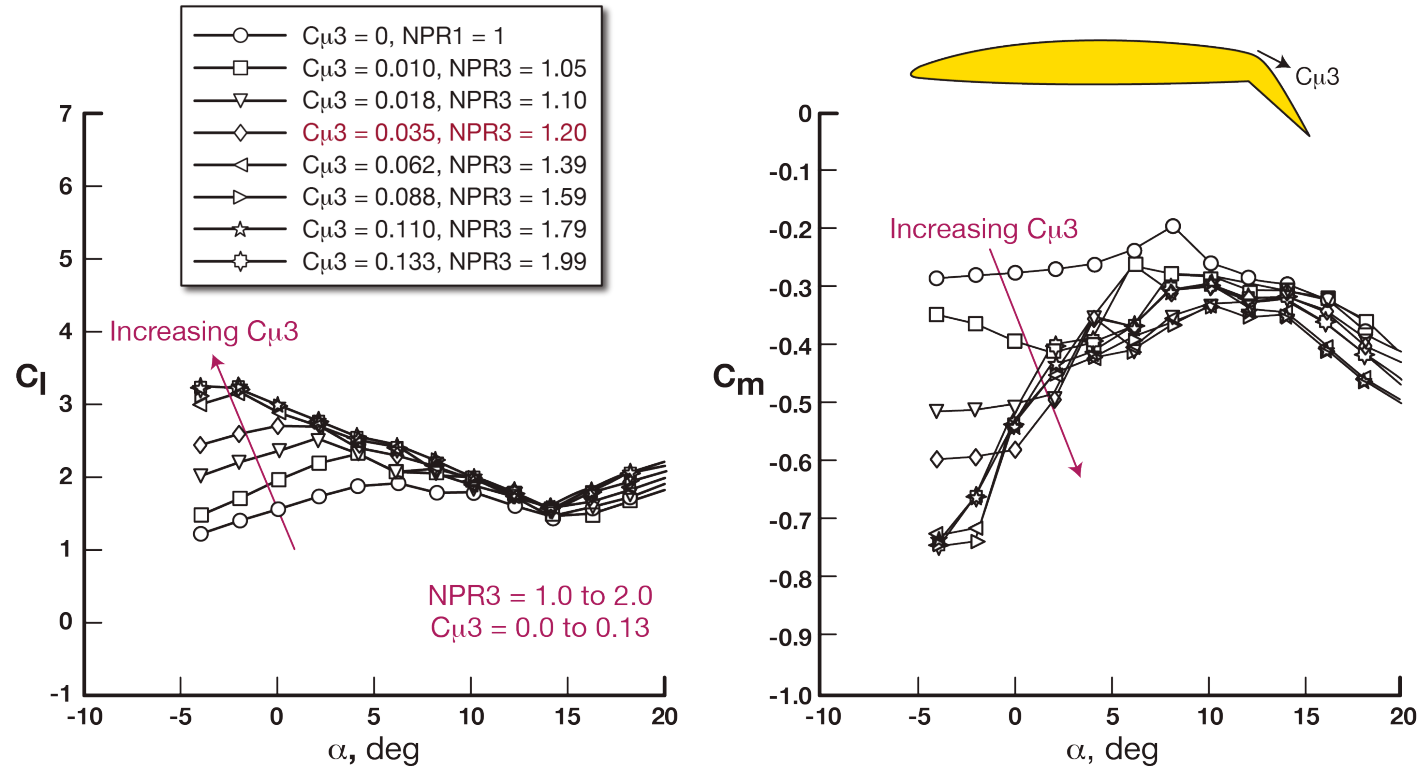

Figure 6. Effect of TE flap blowing (80\% chord, $\mathrm{C} \mu 3)$ on section lift and moment curves.

In Figure 7 the results are shown for the effectiveness of single slot blowing at the $1 \%$ chord location on the LAVLET model. This study was performed to assess and fix the forward blowing coefficient $(\mathrm{C} \mu 1)$ on the leading edge slot, where the TE slot is fixed at $\mathrm{C} \mu 3=0.035$ (NPR2 $=1.2$ ) and the blowing at $10 \%$ chord slot $(\mathrm{C} \mu 2)$ is off. The $1 \%$ chord slot NPR1 is systematically increased from 1.0 to 2.0 . The section lift coefficient $\left(\mathrm{C}_{1}\right)$ curves and moment coefficient $\left(\mathrm{C}_{\mathrm{m}}\right)$ curves versus alpha are shown. As the $\mathrm{C} \mu 1$ is increased from the most forward slot, the lift increases and the negative (nose-down) pitching moment increases commensurately. Increasing $\mathrm{C} \mu 1$ does not affect the stall angle notably as it stays around at 0 to 2 degrees, however the stall seems to be slightly milder (flatter lift curve near maximum lift) for the case of $\mathrm{C} \mu 1=0.057$. 

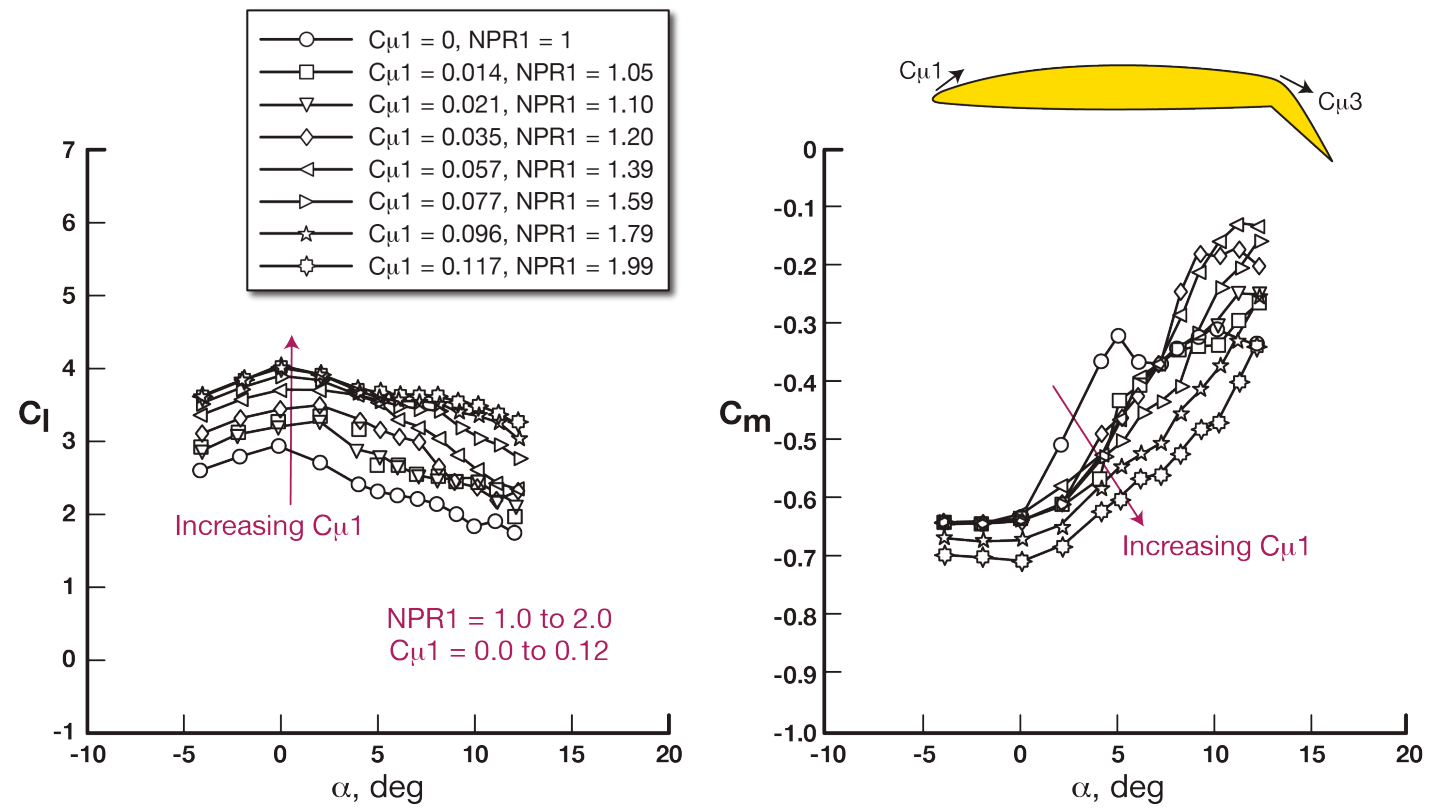

Figure 7. Effect of $1 \%$ chord slot blowing $(\mathrm{C} \mu 1)$ on section lift and moment curves for the LAVLET configuration; $\mathrm{C} \mu 3=0.035$.

Figure 8 shows the lift and moment results for both the $1 \%$ chord and the $10 \%$ chord slot blowing varied equally in NPR from 1.0 to 1.9. Notice that NPR of 2.0 was not achievable on the $10 \%$ chord slot. As equal NPRs are achieved on the forward slots, a maximum section lift of $\mathrm{C}_{1}=4.6$ is achieved. Stall is more benign with increased blowing as blowing from the second slot $(\mathrm{C} \mu 2)$ delayed the LE separation and thereby enhanced the range of maximum lift. The increase in nose-down pitching moment is similar to that of the $1 \%$ chord blowing only.

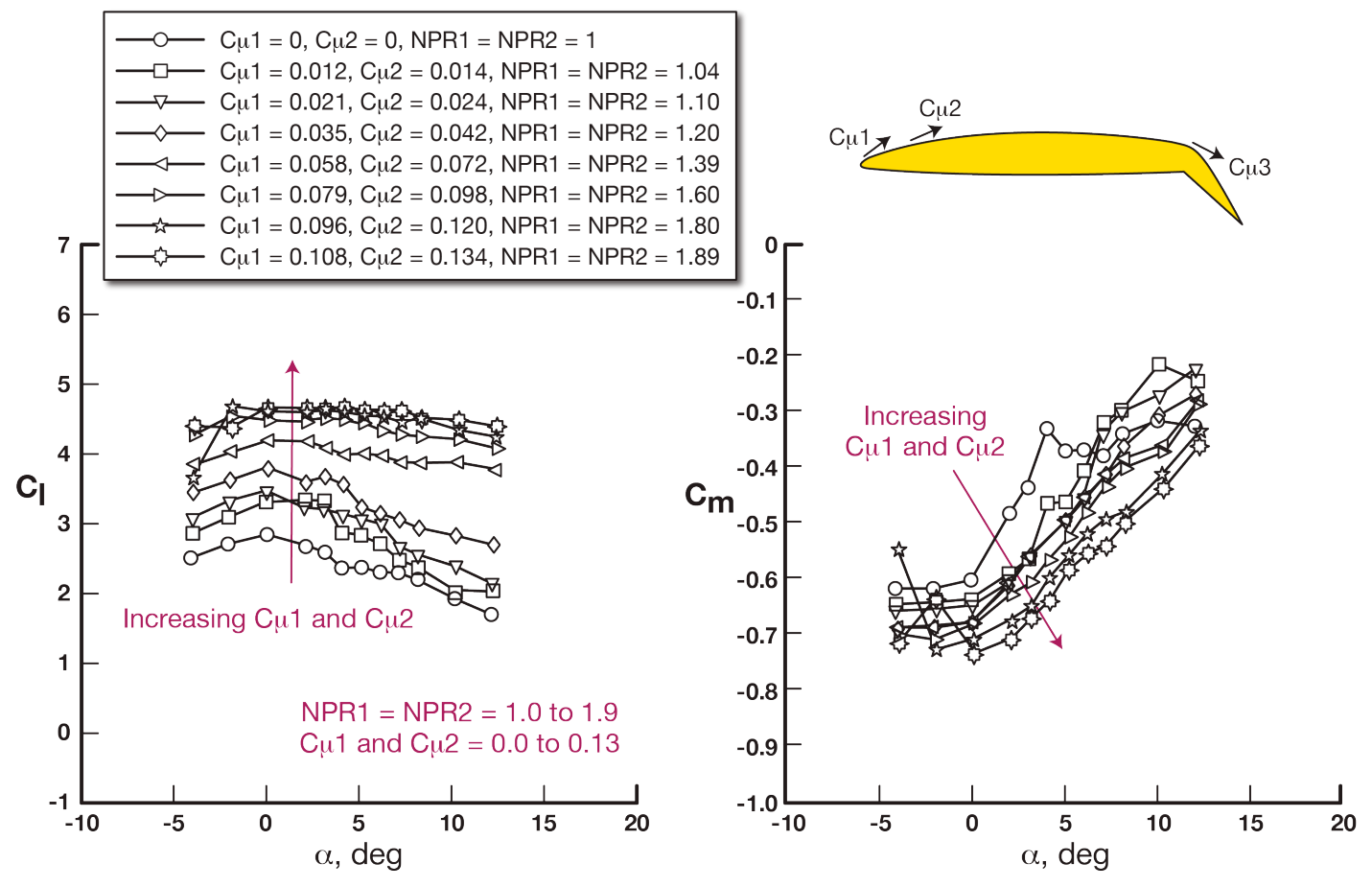

Figure 8. Effect of equal LE slot blowing at $1 \%$ chord $(\mathrm{C} \mu 1)$ and $10 \%$ chord $(\mathrm{C} \mu 2)$ on section lift and moment curves for the LAVLET configuration; $\mathrm{C} \mu 3=0.035$. 
The final LAVLET configuration test is shown in Figure 9. These results are reported for 1\% chord and 10\% chord slot blowing varied differentially in NPR. The blowing from the $10 \%$ chord slot $(\mathrm{C} \mu 2)$ was incrementally adjusted from NPR2 of 1.0 to 1.9 . NPR1 on the $1 \%$ chord slot was fixed at $1.4(C \mu 1=0.056)$. This value was set based on the efficiency evaluations of the equal blowing results from Figure 8. Figure 9 shows that differential blowing could also achieve a maximum lift coefficient of 4.6 and a gradual stall characteristic. Comparing with Figure 8, the significance of this result is that the same level of maximum lift coefficient (4.6) was achieved with a $21 \%$ reduction in total LE C $\mu$ (i.e., $\mathrm{C} \mu 1+\mathrm{C} \mu 2$ reduced from 0.24 to 0.19 ). The wind tunnel data of the LAVLET configuration are also compared with CFD prediction, as shown in Figures 10 and 11.
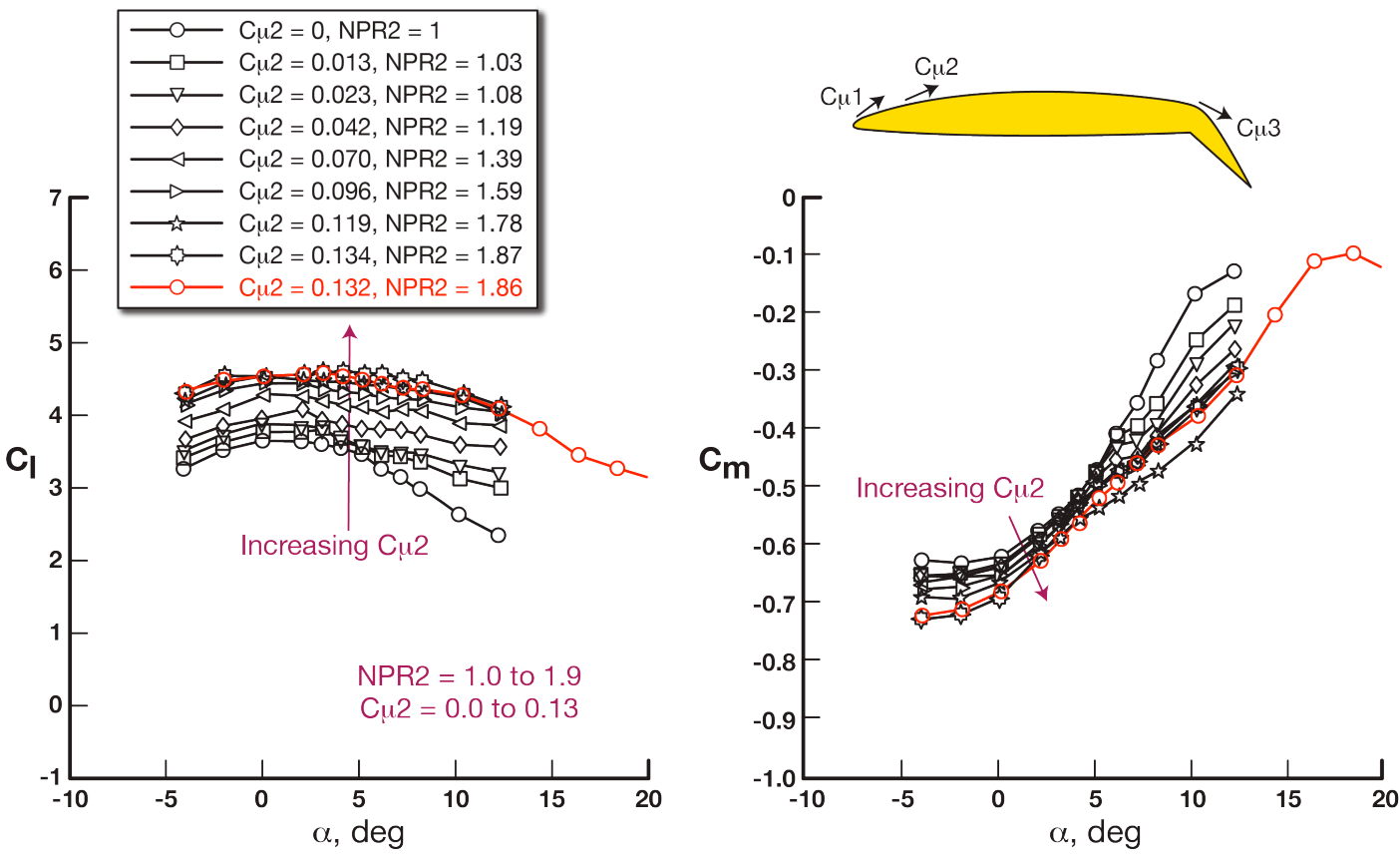

Figure 9. Effect of differential LE slot blowing with varying LE blowing at $10 \%$ chord $(\mathrm{C} \mu 2)$ on section lift and moment curves for the LAVLET configuration; $\mathrm{C} \mu 1=0.056$ and $\mathrm{C} \mu 3=0.035$.
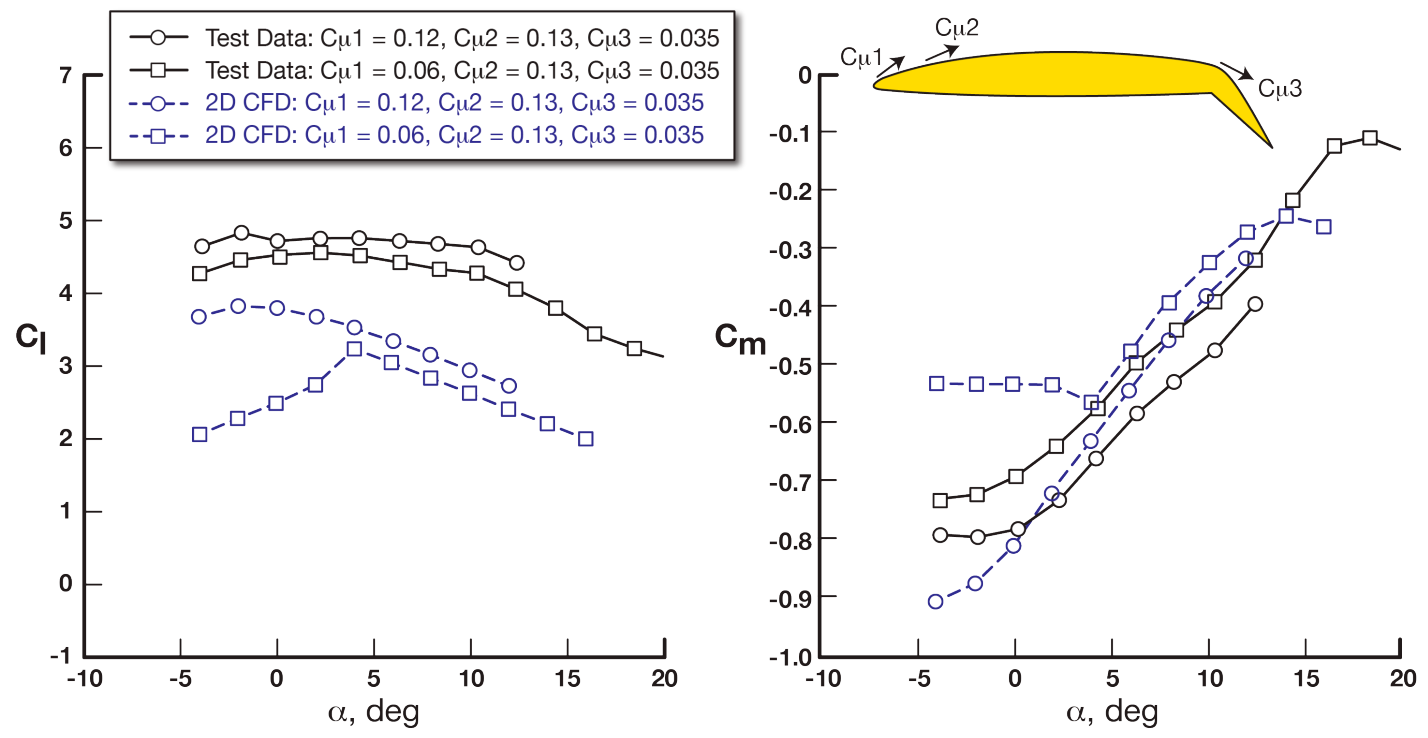

Figure 10. Comparison of CFD and experimental results for section lift and moment curves of the LAVLET configuration with varying LE blowing at $1 \%$ chord $(C \mu 1), C \mu 2=0.13$ and $C \mu 3=0.035$. 
Figure 10 shows the lift and moment curves of LAVLET (plotted in black) versus CFD predictions (plotted in blue). The magnitude of lift curves is under predicted by the CFD. The general shape of the lift and moment curves is representative of the test data for $\mathrm{C} \mu 1=0.12$, however, $\mathrm{CFD}$ over predicted LE flow separation at lower angles of attack (-4 to 2 degrees) for the lower blowing case $(\mathrm{C} \mu 1=0.06)$, resulting in the loss of lift and less negative moment.

Figure 11 shows that good correlation exists between the pressure distribution data and the lower surface predictions. The suction pressures on the upper surface were generally under predicted. As was seen with the lift and moment data, the integrated $\mathrm{Cp}$ distributions require further analysis between the first and second LE blown slots as well as just downstream of the latter. CFD predictions had identified some highly complex flows in these regions.

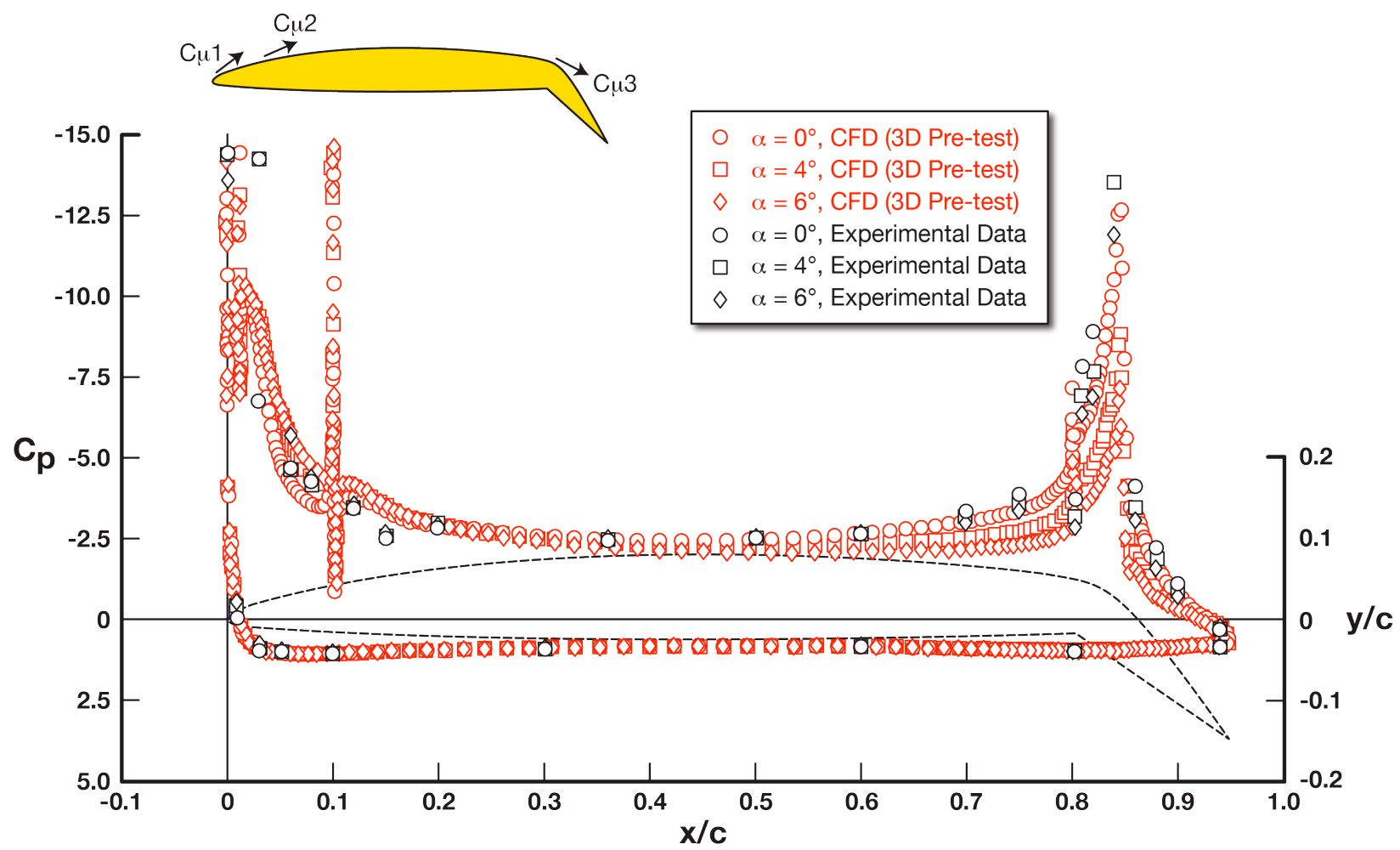

Figure 11. Comparison of CFD and experimental results for pressure distributions of the LAVLET configuration at various angles of attack; $\mathrm{C} \mu 1=0.12, \mathrm{C} \mu 2=0.13$, and $\mathrm{C} \mu 3=0.04$.

Figure 12 shows the results for slot blowing at $12 \%$ chord $(\mathrm{C} \mu 2)$ on the MOLEC configuration. The TE blowing is fixed at $\mathrm{C} \mu 3=0.035$ (NPR3 $=1.2$ ) as was the case for LAVLET. NPR2 was varied on the $12 \%$ chord slot from 1.0 to 2.0. The section lift and moment versus angle of attack curves are shown. With shoulder blowing, MOLEC achieves a remarkable $C_{1}=5.0$. Stall angle becomes significantly delayed $\left(\sim 10^{\circ}\right)$, as well as more negative pitching moment, with increasing $\mathrm{C} \mu 2$ when comparing to the LAVLET LE blowing.

The blown MOLEC configuration was tested to examine the effect of q variation (see Figure 13). The dynamic pressure, q, was varied from $10 \mathrm{psf}$ to $60 \mathrm{psf}$ while the NPR on the $12 \%$ chord slot was fixed at 1.8 and the NPR on the TE slot was fixed at 1.2. An extraordinary high lift value $\mathrm{C}_{1}=7.0$ was achieved during the $q$ sweep for the lowest q (10 psf), which demonstrated the significant of this high-lift concept at very low speeds.

In Figure 14, the lift and moment curves are assessed against CFD predictions for the MOLEC configuration. The wind tunnel data appears in black, the 3D pre-test predictions are shown in red and the conceptual design $\left(\operatorname{Re}_{\mathrm{c}}=\right.$ 22 million) predictions are shown in green. The test data shows that the (best) blown MOLEC configuration achieves a maximum $C_{1}$ of 5.2. Stall becomes significantly delayed with increased $C \mu$. The general shape of all curves is roughly the same with an under-prediction of $\mathrm{C}_{1}$ values for the blowing case. CFD predicted the pitching moment reasonably well for both LE blowing and non-blowing cases. 

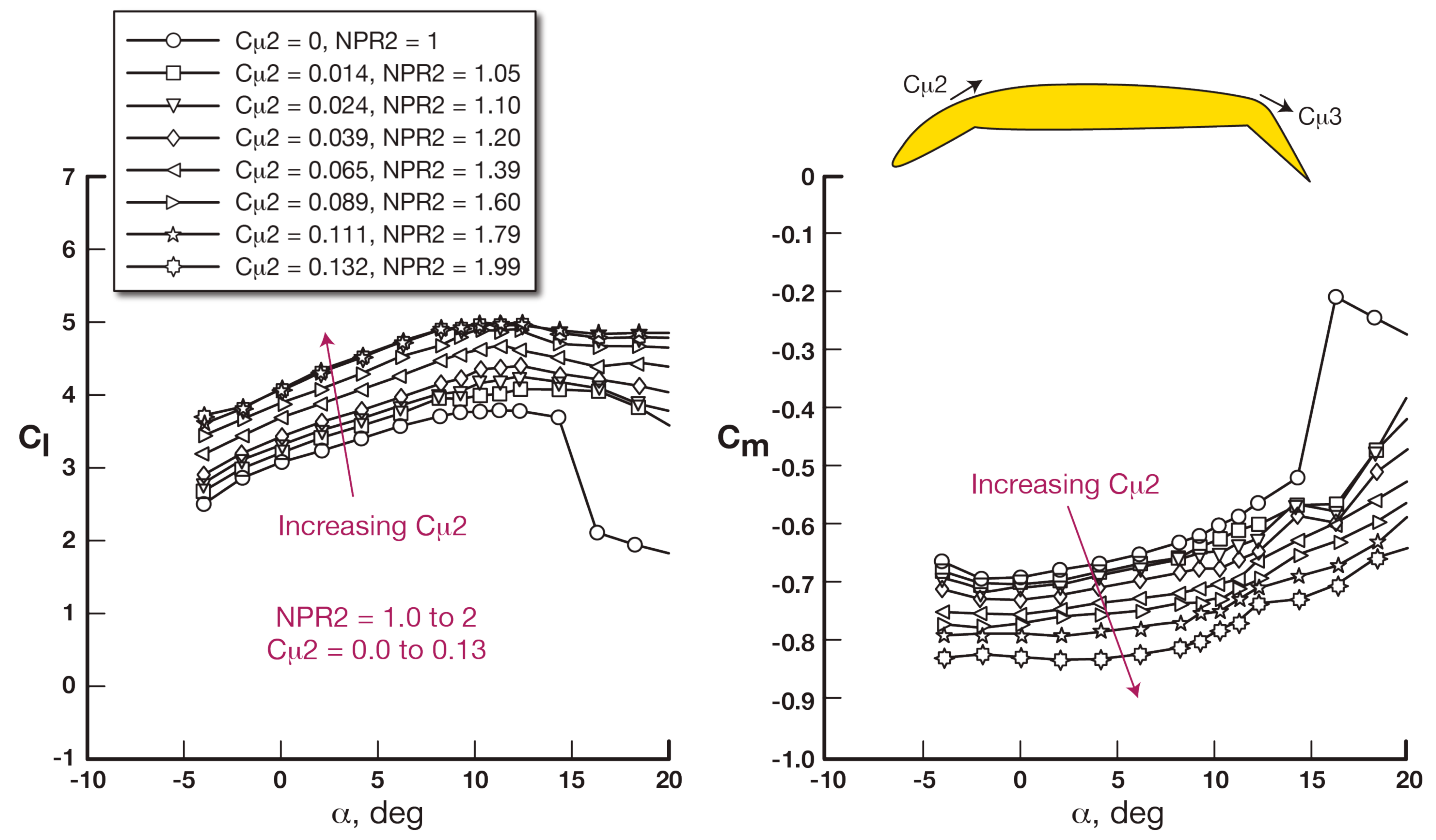

Figure 12. Effect of $12 \%$ chord slot blowing $(\mathrm{C} \mu 2)$ on section lift and moment curves for the blown MOLEC configuration; $\mathrm{C} \mu 3=0.035$.
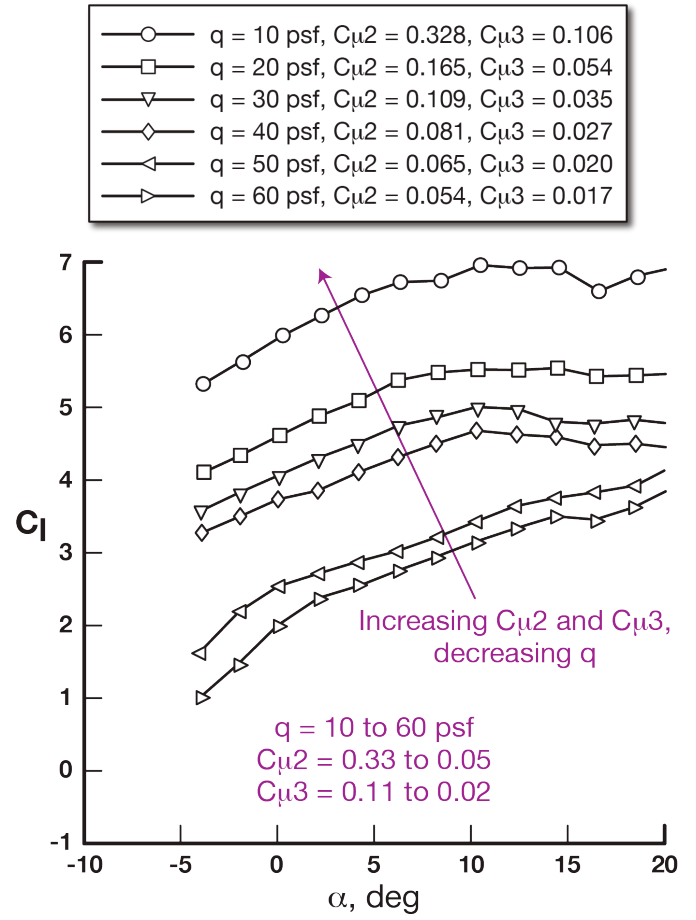
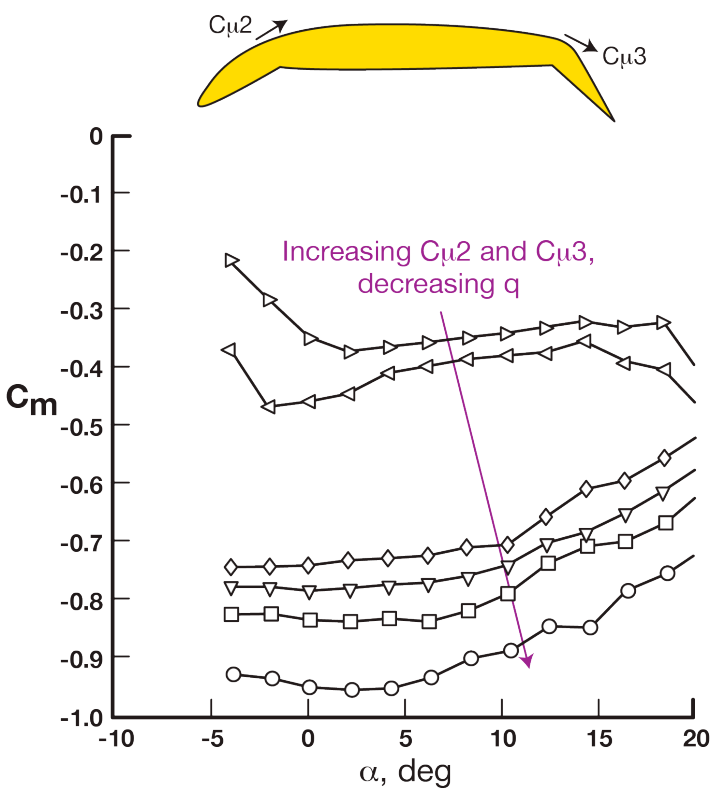

Figure 13. Effect of q on section lift and moment curves for the blown MOLEC configuration; NPR2 = 1.8, NPR3 = 1.2 . 


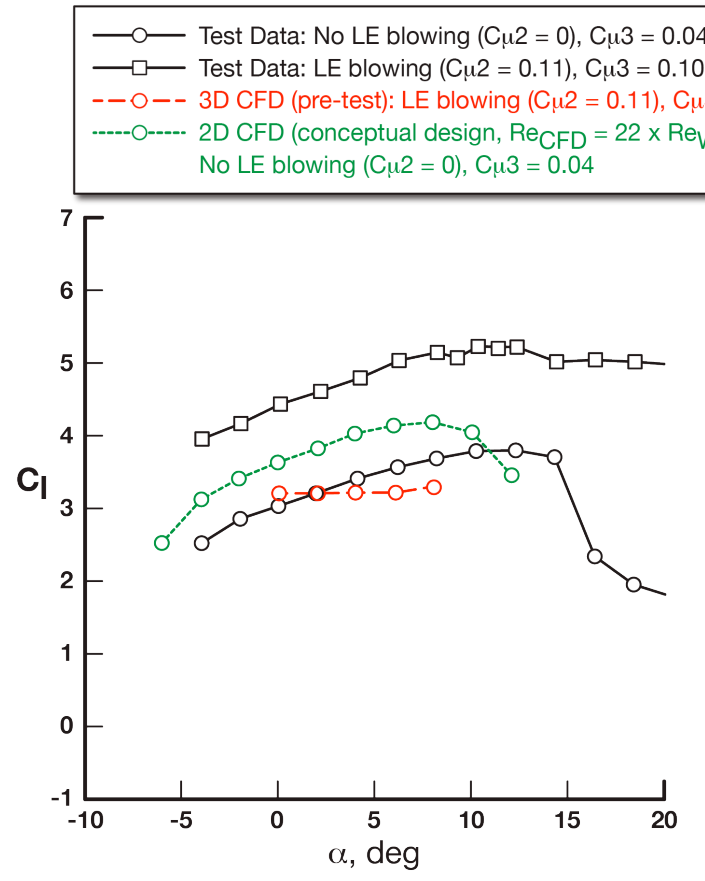

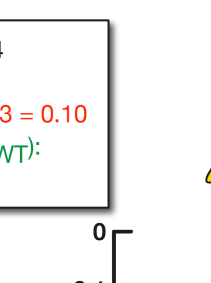
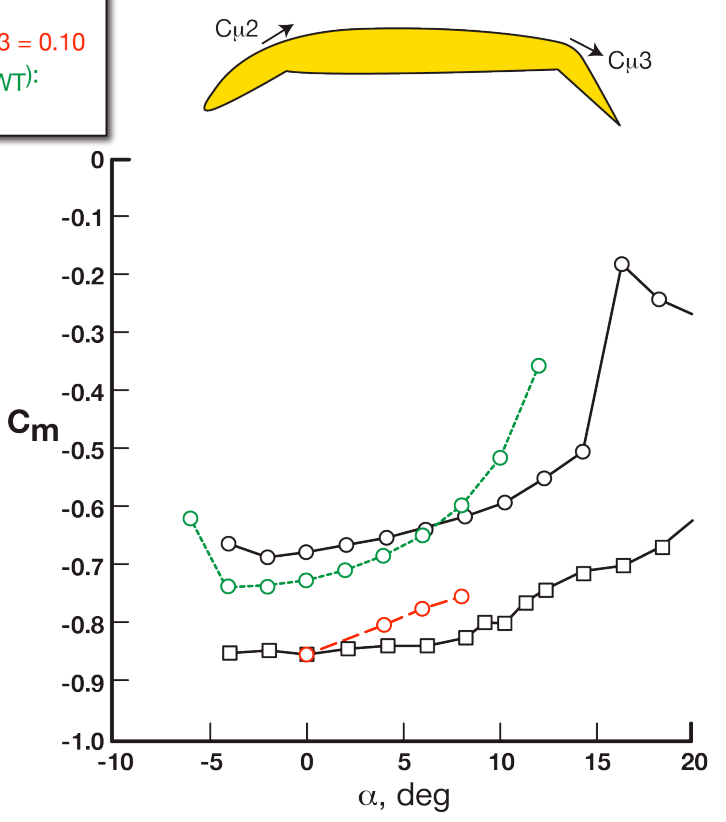

Figure 14. Comparison of CFD and experimental results for section lift and moment curves of the MOLEC configuration with and without LE blowing at $12 \%$ chord $(\mathrm{C} \mu 2)$.

The Cp distributions were generated for wind tunnel test data versus CFD pre-test predictions (see Figure 15). CFD predictions show good correlation on the MOLEC model for the lower surface. The upper surface predictions for all angles of attack show significant differences in pressure magnitudes but consistent behavior in general shapes. This is likely attributed to the complexity of the flows at the leading edge slot. Again, further analysis is recommended to investigate flow physics of the complex slot flows, especially around the LE slot.

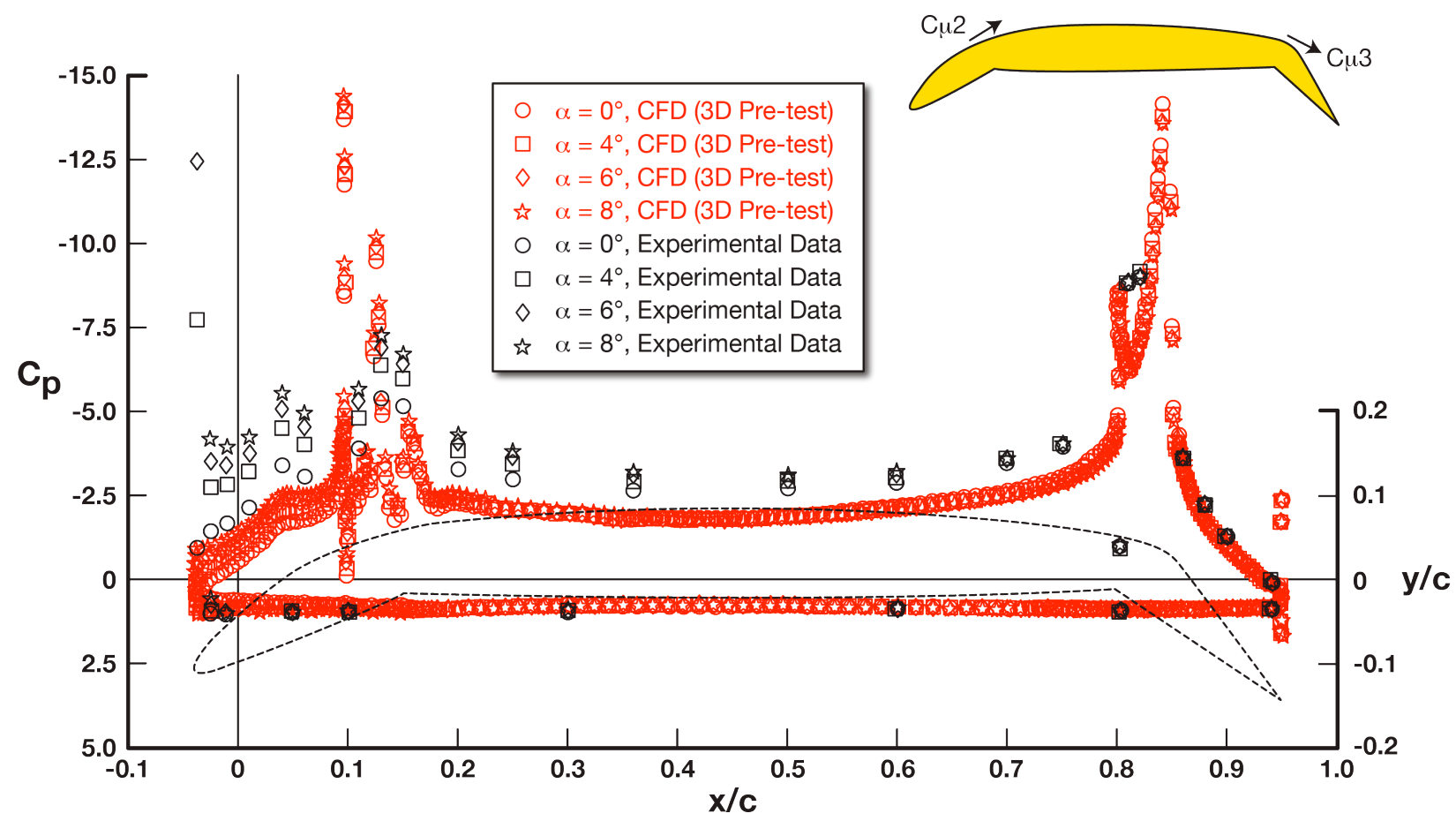

Figure 15. Comparison of CFD and experimental results for pressure distributions of the MOLEC configuration at various angles of attack; $\mathrm{C} \mu 2=0.11$, and $\mathrm{C} \mu 3=0.10$. 
Figure 16 compares and summaries the lift and incremental lift data for AHLLE configurations for the nominal trailing edge blowing of $C \mu=0.035$. The lift curve indicates that the LAVLET $(\operatorname{LE} C \mu=0.19$ : $C \mu 1(0.056)+$ $\mathrm{C} \mu 2(0.134)$ ) achieved a maximum $\mathrm{C}_{1}$ of 4.6 , while the MOLEC (morphing, no LE blowing) achieved a maximum $\mathrm{C}_{1}$ of 3.8, and blown MOLEC (morphing, $\mathrm{LE} C \mu=0.11$ ) achieved a maximum $\mathrm{C}_{1}$ of 5.0.

LAVLET (LE blowing) achieved $C_{I}=4.6(\operatorname{LE} C \mu=0.19)$

MOLEC (morphing) achieved $C_{\mid}=3.8(\operatorname{LE} C \mu=0)$

Blown MOLEC (morphing) achieved $C_{\mid}=5.0($ LE C $\mu=0.11)$

\begin{tabular}{|ll|}
\hline Un-Powered High Lift (NACA 64A010) & Powered Lift Concepts \\
Conv. 1 - LE Slat + TE Split Flap & Conv. 5 - Vectored Thrust \\
Conv. 2 - LE Flap + TE Split Flap & Conv. 6 - Externally Blown Flap \\
Conv. 3 - LE Slat + TE Double Slotted Flap & Conv. 7 - Upper Surface Blown Flap \\
Conv. 3 - LE Flap + TE Double Slotted Flap & Conv. 8 - Internally Blown Flap \\
\hline
\end{tabular}

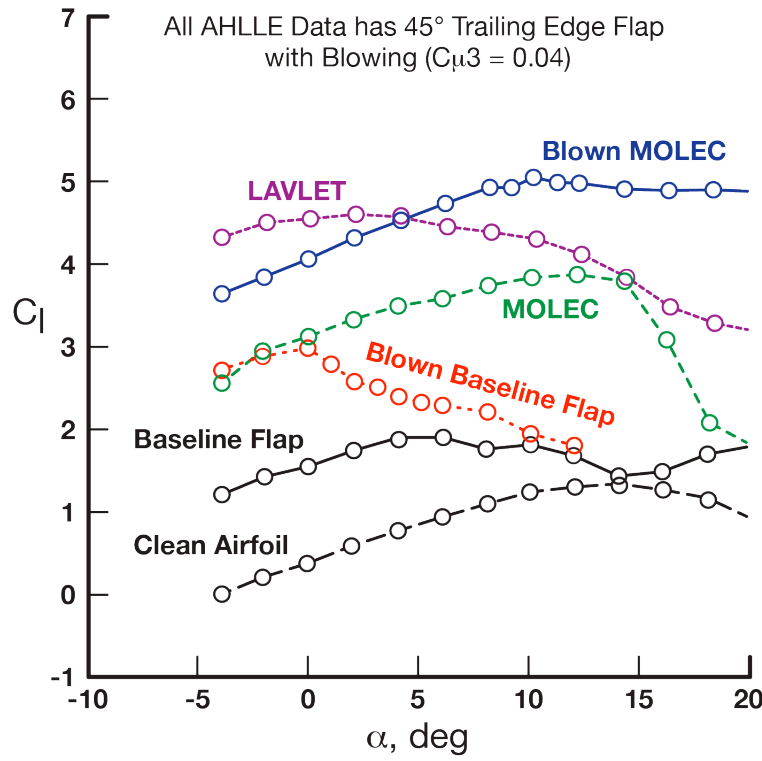

Figure 16. AHLLE result summary and high-lift configuration comparisons.

Figure 16 also summarized the lift increment with respect to the reference high lift, which is the 45-degree flap deflection without TE blowing. Various modern convention high lift system were also included in the plot for comparison. With the exception of the powered-lift systems, LAVLET and Blown MOLEC concepts compare favorably with most of these conventional high lift systems. For example, the best AHLLE results yielded up to 94\% lift improvement over the conventional Krueger flap high-lift configurations while allowing laminar flow possibility during cruise, which could have numerous commercial applications.

\section{Concluding Remarks}

The AHLLE program examined several high lift leading edge concepts that are compatible with laminar flow in the cruise configuration. The program examined ten configurations in a conceptual design process that included aerodynamic analysis (CFD) and structural design assessment. The configurations were assessed during a down selection process that included QFD analysis to determine two final candidates for wind tunnel test. The QFD analysis included weighting factors such as high lift capability, laminar flow compatibility, weight, structural design, complexity, acoustics, power, maintainability, and TRL. The resulting candidates for ground test were a blown leading edge (LAVLET) configuration that created a virtual slat through two leading edge slots (1\% and $10 \%$ chord). A second configuration was a drooped (morphed) leading edge configuration (MOLEC) that included a spanwise blowing slot at $12 \%$ chord. All models had a common blown flap deflected to 45 degrees.

In the final analysis, the entire AHLLE project was completed in 13 months from conceptual development to wind tunnel testing. The two AHLLE configurations were successfully wind tunnel tested to TRL of 4 . The AHLLE project successfully developed enabling high-lift leading-edge technology and exceeded the target goals for 
lift improvement by around $30 \%$ with a maximum section lift coefficient $\left(\mathrm{C}_{1, \max }\right)$ of 5.2. Maximum incremental section lift coefficient $\left(\Delta \mathrm{C}_{\mathrm{l}}\right)$ of 3.5 and 3.1 was achieved for a blown MOLEC concept and a LAVLET concept, respectively. In addition, both LAVLET and blown MOLEC concepts exhibit mild stall characteristics and nosedown pitching moment. Wind tunnel results indicated better lift enhancement for the AHLLE concepts than what CFD had predicted. Further analysis is recommended to investigate flow physics associated with the complex slot flows, especially around the leading edge slots. The AHLLE efforts demonstrated two advanced high-lift concepts that yielded up to $94 \%$ lift improvement over the conventional Krueger flap high-lift configurations while allowing laminar flow possibility during cruise.

\section{References}

1. Joslin, R., “Overview of Laminar Flow Control,” NASA/TP-1998-208705, October 1998.

2. Collins, S., "Extreme Short Takeoff and Landing Aircraft Dual-Use Technology Study," NAS2-03001 T002 Final Report, November 28, 2005.

3. Wang, D., Bartley-Cho, J., Kjerstad, K., Kwon, H., Rahrig, K., Schein, D., Ho, B., and Speer, S., “MultiObjective Leading Edge Concepts (MOLEC)," NASA Contractor Report, June 30, 2009.

4. Collins, S. W., Westra, B. W., Lin, J. C., Jones, G. S., and Zeune, C. H., "Wind Tunnel Testing of A Powered Lift All-Wing STOL Model,” The Aeronautical Journal, v. 113, no. 1140, February 2009, pp. 129-137.

5. Lin, J. C., Jones, G. S., Allan, B. G., Westra, B. W., Collins, S. W., and Zeune, C. H., "Flow-Field Measurements of a Hybrid Wing Body Model with Blown Flaps," AIAA 2008-6718, 26 ${ }^{\text {th }}$ Applied Aerodynamics Conference, Honolulu, HI, August 2008.

6. Drake, A., Bender, A., Korntheuer, A., Westphal, R., McKeon, B., Gerashchenko, S., Rohe, W., and Dale, G., "Step Excrescence Effects for Manufacturing Tolerances on Laminar Flow Wings," AIAA 2010-0375, 48 AIAA Aerospace Sciences Meeting and Exhibit, Orlando, FL, January 2010.

7. Su, W., and Cesnik, C., "Nonlinear Aeroelasticity of a Very Flexible Blended-Wing-Body Aircraft," AIAA 2009-2402, 50 ${ }^{\text {th }}$ AIAA/ASME/ASCE/AHS/ASC Structures, Structural Dynamics, and Materials Conference, Palm Springs, CA, May 2009.

8. Malone, M. B., “Turbulence Model Evaluation for Free Shear Dominate Flows," AIAA 96-2038, 27" AIAA Fluid Dynamics Conference, New Orleans, LA, June 1996.

9. Kinzie, K. W., Schein, D. B., and Solomon, W. D., "Experiments and Analyses of Distributed Exhaust Nozzles," AIAA 2002-2555, $8^{\text {th }}$ AIAA/CEAS Aeroacoustic Conference, Breckenridge, CO, June 2002. 